\title{
The German adhesives industry forecasts 3\% growth
}

The annual conference of the German Adhesives Association (IVK) in Hamburg focused on the subject of economic recovery. A total of 251 representatives of 88 of the 123 member companies attended this year's conference with the aim of finding out more about current economic trends and the association's latest activities.

In Germany the adhesives market has traditionally seen stronger growth than GDP. The results of a recent survey show that the German adhesives industry is expecting to see a $3 \%$ growth in sales across all its target industries this year, despite economic uncertainties. The growth drivers include private consumption and foreign trade, which has benefited from the strong demand for German products outside the euro area. In addition, low interest rates are encouraging house building and investment. The threats to growth in Germany include the European banking and economic crisis, the ongoing increase in raw material prices, which has now slowed down, and the shortage of skilled staff.

\section{Training initiative}

Among the many areas where the association is active on behalf of its members, training is growing in importance, not least because of the need to combat the lack of skilled workers. For this reason, the association has launched an initiative to raise awareness among school pupils and students about the jobs of the future in the adhesives industry. This training initiative for the adhesives industry will also help to ensure that the industry is included in the campaign started by the German Federation of Chemical Employers' Associations (BAVC) entitled "Elementare Vielfalt” (Fundamental diversity). In its description of the different jobs (such as chemical engineer, chemical lab technician etc.), the association will also mention the fact that adhesives companies provide training. The training campaign "Komm kleben..." (Find out more about adhesives) is available as a film. Another source of information is the website www.kommkleben.de, which acts both as a communication platform and as a job and training portal for newcomers to the industry. The website includes details of training courses, job descriptions and vacancies and provides background information about the industry and individual adhesives companies. The campaign also uses social media sites such as Facebook.
The perfect complement to the association's training programme is a set of interactive guidelines which it has developed together with the Fraunhofer Institute for Manufacturing Technology and Advanced Materials (IFAM) concerning the right methods of using adhesives, which is available on the Internet. An English version has also been produced.

Together with the FWU (the media institute of the Federal German States), the German Adhesives Association has successfully created two informational DVDs entitled "Grundlagen des Klebens" (The fundamentals of using adhesives) and "Kleben in Handwerk und Industrie" (Adhesives in trade and industry). The DVDs consist of a number of films which describe the fundamental methods of using adhesives, correct bonding processes and bonding wood, metal and plastics using practical examples. The DVDs also have interactive learning assessments.

For more information: www.klebstoffe.com

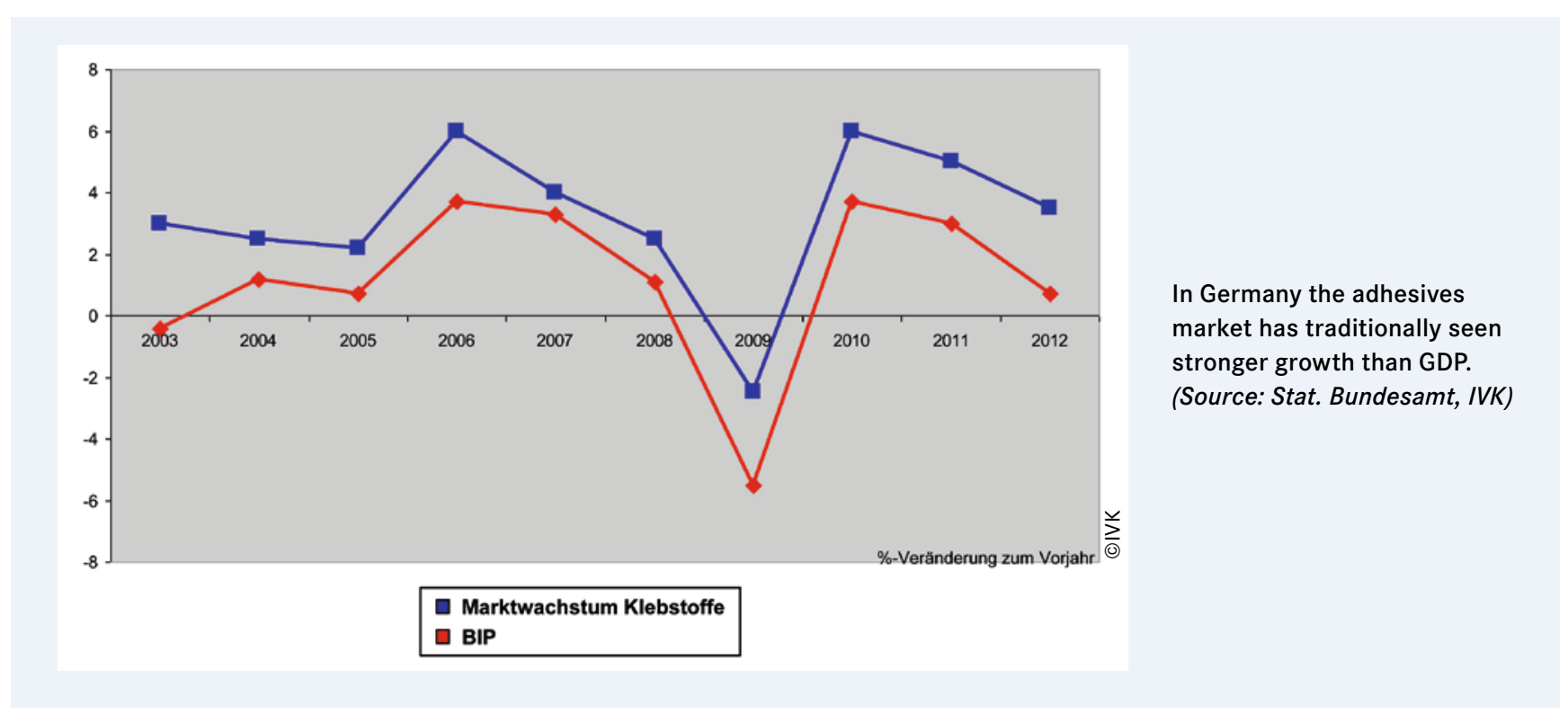

